\title{
Some Features of the Surface Micro- and Macroprofile Formation at Flat Face Grinding with Spindle Axis Inclination
}

\author{
KUNDRÁK János ${ }^{1, ~ a ~, ~ F E D O R O V I C H ~ V l a d i m i r ~}{ }^{2, ~ b}$ PYZHOV Ivan $^{2, ~ c ~}$, \\ MARKOPOULOS Angelos ${ }^{3, d}$ and KLIMENKO Vitaly ${ }^{4, e}$ \\ ${ }^{1}$ Institute of Manufacturing Science, University of Miskolc, Miskolc, Hungary \\ ${ }^{2}$ Department of Integrated Engineering Techniques n.a. M.F.Semko, National Technical University \\ "Kharkiv Polytechnic Institute", Kharkov, Ukraine \\ ${ }^{3}$ Section of Manufacturing Technology, School of Mechanical Engineering, National Technical \\ University of Athens, Heroon Politechniou 9, 15780, Athens, Greece \\ ${ }^{4}$ Department of Manufacturing Engineering, National Technical University, Poltava, Ukraine \\ akundrak@uni-miskolc.hu, ${ }^{b}$ fedorovich@kpi.kharkov.ua, ${ }^{c}$ diamet@inbox.ru, \\ damark@mail.ntua.gr, diamet@inbox.ru
}

Keywords: flat face grinding, spindle inclination angle, grinding wheel, line feed, computer-aided simulation, flatness error, concavity, macroprofile, residual ridge.

\begin{abstract}
The work described in this paper pertains to the identification of some features of microand macroprofile formation of surfaces to be machined with flat face grinding, with inclination of the spindle axis. The question of the formation of machined surface profile at through-feed grinding and multiple-pass scheme are considered by using computer-aided simulations in COMPASS environment. More specifically, for flat face through-feed grinding, a generalized empirical equation exhibiting the dependency of concavity from the outer diameter of the face grinding wheel, the spindle axis inclination angle and the width of the surface of the workpiece is acquired. Furthermore, based on the maximum allowable value of flatness deviation and with pre-determined grinding wheel diameter and workpiece width, it is possible to identify the maximum inclination angle at which concavity falls within acceptable limits. For the case of multiple pass flat face grinding, the role of factors such as inclination angle of spindle axis, cross-feed and diameter of the grinding wheel on the height of residual ridges on the surface of the parts is determined through the proposal of an empirical equation. With the aforementioned equations the machinist may reasonably prescribe machining conditions in practice. The conducted research contributes to the expansion of ideas regarding technological possibilities of improvement of flat face grinding.
\end{abstract}

\section{Introduction}

Flat face grinding is a necessary step in a significant number of products with various applications in many industrial sectors $[1,2,3,4]$. Grinding machines with vertical spindle, which provide processing with the end face of the grinding wheel, are widely used. These machines may be equipped with either rotational or rectangular tables and also bilateral machines are used, which can provide simultaneous processing to the surface of the workpiece, on both sides. Grinding machines with vertical spindle ensure high productivity and working accuracy under sufficiently low roughness of the machined surface. These machines are designed for grinding of flat surfaces under conditions of mass and batch production. On conditions that the diameter of the wheel, i.e. the abrasive head, is bigger than the width of the working table, machining is usually carried out according to through-feed scheme, as it has beneficial effect on the values of output parameters of processing. If necessary, processing can be carried out using a multiple-pass scheme. In rough grinding, the spindle of the grinding wheel head is inclined horizontally towards line feed. Thus, due to the reduction of the wheel working surface contact area with the workpiece, it is possible to avoid overheating and strain of the processed part and achieve a significant increase in the 
productivity of processing $[5,6]$. In some cases, inclination of wheel contributes beneficially to fluid delivery in the grinding zone [7]; at finishing stage, inclination of the spindle is reduced, and in the case of precision grinding, no inclination is recommended to be applied.

Manufacturing capability enhancement for flat face grinding is of special interest in contemporary industry; several novel technical solutions, correlated with patents, have been proposed. They lie in the field of structural improvements of surface grinding machines by proposing advanced engineering solutions. These solutions provide the conditions for the realization of grinding in a layer of process liquid and provide the possibility of implementing both preliminary grinding and final polishing at vibration grinding conditions [8], improve the design of devices for effective delivery of process fluid in the area of grinding and dressing of the wheel [9], monitor the degree of filling of these zones with process fluid [10], increase the efficiency of abrasive wheel working surface dressing with diamond dressers $[11,12]$ and reduce contact area of wheel working surface with workpiece by initial inclination of the spindle axis. The latter suggestion is a quite simple solution for controlling the contact area of wheel working surface with workpiece surface and hence the thermo-mechanical intensity of grinding. The aforementioned novel solutions increase significantly the efficiency of flat face grinding on grinding machines with vertical spindle.

In the research presented in this paper the scheme of flat face grinding with initial inclination of the spindle axis of the grinding wheel is considered. The drawback of the scheme is the inevitable increase in roughness and the form deviation of the final workpiece surface for inclined wheel working surface. When through-feed grinding is discussed, a special case of flatness deviation, namely concavity, is observed [13]. In the case of multiple-pass grinding, residual ridges form the micro - and macroprofile of the final product surface [14]. To the authors' knowledge, no studies related to the mechanisms and features of form deviations of flat surfaces according to the described grinding schemes exist in the relevant literature, up to date. Implementation of the proposed grinding process without spindle axis inclination is not advantageous, so spindle inclination is unavoidable. However, if this feature is not taken into account, it could lead to uncertainty in the calculation of allowances for final grinding and result to defective final products. The aim of this research is to identify the formation of micro- and macroprofile features of product surfaces at flat face grinding with spindle axis inclination and fill the gap created by the lack of studies connected to this process.

\section{Features of Flat Face Through-Feed Grinding}

Flat face grinding process can be implemented in practice according to classical and deep grinding scheme, depending on the direction of the line feed $\mathrm{S}$ of grinding machine table relative to the direction of inclination angle of spindle axis $\alpha$, see Fig. 1 and Fig. 2 as left side and top view of the process, respectively.

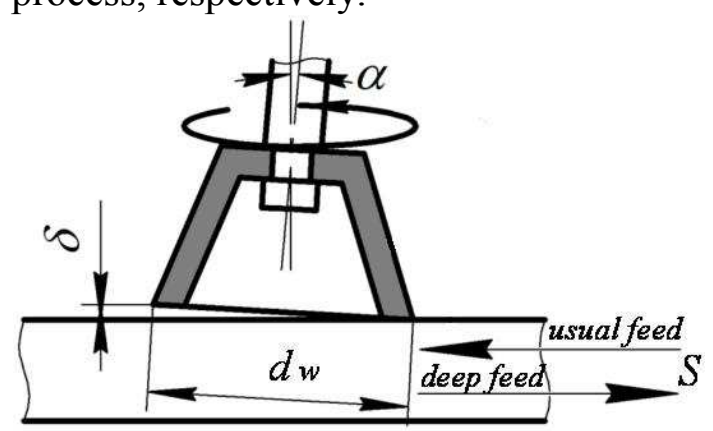

Fig. 1. Classic and deep grinding schemes

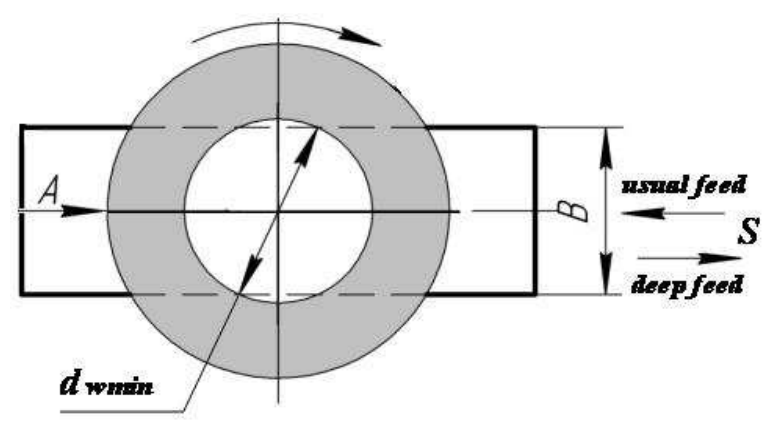

Fig. 2. Top view of the grinding scheme

In the case of through-feed grinding, diameter of wheel $d_{w}$ is exceeding the workpiece width B. At the same time, it is desirable that the wheel minimum diameter $d_{w}$ min to be greater than workpiece width B, too. Flat face grinding in which spindle axis is accompanied by an inclination angle towards the longitudinal movement of the grinding machine table, has a significant drawback, 
namely the appearance of flatness deviations. The bigger the width of the surface being machined during through-feed grinding, higher flatness deviations are anticipated. In the relevant literature there are no clear guidelines for determining the inclination angle $\alpha$, only values of the gap between the wheel and workpiece; $\delta=2 \mathrm{~mm}$ for roughing and $\delta=0,05 \mathrm{~mm}$ for finishing $[5,6]$.

However, wheel diameter, which directly affects the value of the angle, is not considered. If the wheel working surface is given an infeed, it immerses in the processing surface at depth $t$ and is almost completely in contact with the workpiece. In the deep feed variant under the condition $B \geq d_{w}$, the inclination angle is given as:

$\alpha=\arcsin \left(\frac{t}{d_{w}}\right)$.

In the presented study, it is considered that for ensuring the technical requirements for flatness deviation, inclination angle $\alpha$ must be clearly defined, besides taking into account the fact that other factors also have an impact on the form deviation of flat surface. These include the outer diameter of face grinding wheel $d_{w}$ and the width of the surface of the workpiece B. Fig. 3 shows the formation of the flatness deviation $\Delta$ in the process of flat face through-feed grinding, when processing is symmetric. It can be seen that at the first pass, flatness deviation equals the depth of grinding, i.e. $\Delta_{1}=\mathrm{t}$. Then, as several passes of the grinding wheel with depth $\mathrm{t}$ are realized, $\Delta$ gradually increases and equals value $\Delta_{\mathrm{i}}$. Accordingly, the length of the arc of contact between the wheel working surface and the workpiece surface also increases gradually, from $l_{1}$ to $l_{i}$. When the

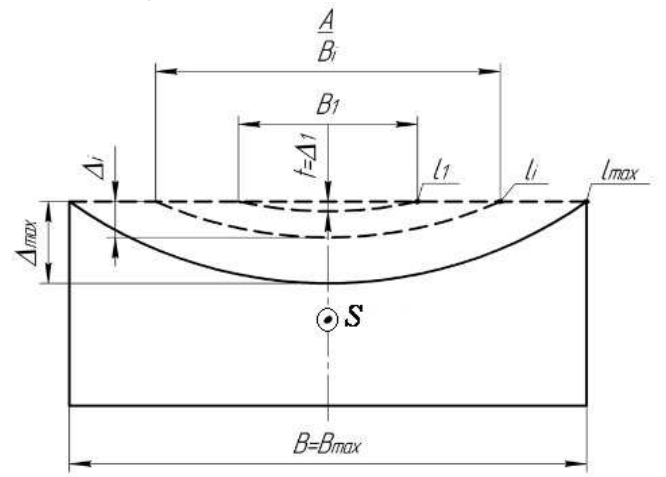

Fig. 3. Formation of flatness deviation at flat face grinding wheel working surface will start contacting with the part across the whole width of the surface being machined, or when $\mathrm{B}$ becomes equal to $\mathrm{B}_{\max }$, then $\Delta$ equals $\Delta_{\max }$ and becomes constant. In turn, this implies that the larger the width of processing $\mathrm{B}$, at constant values of other parameters, the greater the deviation $\Delta$ becomes.

In order to obtain the dependence of the deviation $\Delta$ from the factors mentioned above, investigations by computer-aided simulation software COMPASS [15] were conducted. The simulation results showed that the functions $\Delta=f(\mathrm{~B})$ and $\Delta=f\left(\mathrm{~d}_{\mathrm{w}}\right)$ can be described quite satisfactorily by using power dependencies, see Fig. 4 and Fig. 5, while $\Delta=f(\alpha)$ is linear, see Fig. 6 .

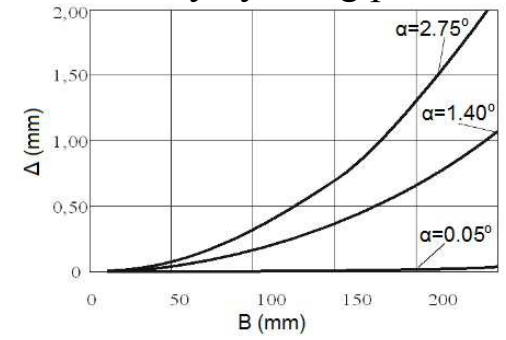

Fig. 4. Workpiece width B versus deviation $\Delta$ for various inclination angles $\alpha$, for $\mathrm{d}_{\mathrm{w}}=400 \mathrm{~mm}$

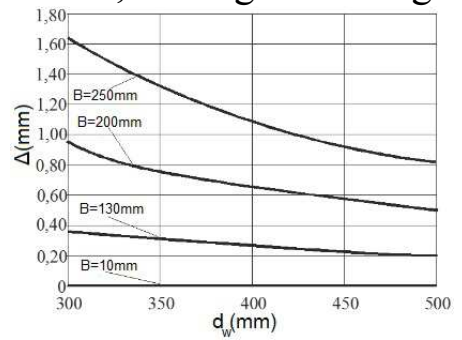

Fig. 5. Grinding wheel diameter $d_{w}$ versus deviation $\Delta$ for various workpiece widths, for $\alpha=1.4^{\circ}$

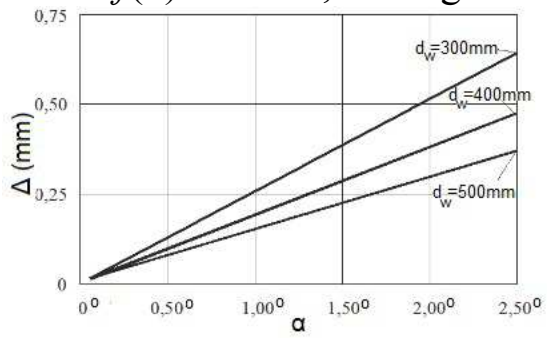

Fig. 6. Inclination angle versus deviation $\Delta$ for various grinding wheel diameters, for $\mathrm{B}=130 \mathrm{~mm}$

It may be concluded that for larger wheel diameter $d_{w}$ and smaller values of workpiece width $B$ and inclination angle $\alpha$, less deviation $\Delta$ will take place at flat face grinding and vice versa. A generalized empirical equation for the dependence of the deviation $\Delta$ from the specified factors was obtained from the simulations. The equation has the form:

$\Delta=0.013 \cdot d_{w}^{-1.196} \cdot \alpha \cdot B^{2.026}$.

Thus, Eq. 2 takes into account for the determination of the level of flatness deviation, in this case the concavity, a connection of $\Delta$ with wheel diameter, workpiece width and inclination angle. Angle 
$\alpha$ at specific values of $\mathrm{d}_{\mathrm{w}}, \mathrm{B}$ and the maximum allowable value of deviation $\Delta_{\max }$, based on technical requirements, must be subjected to the dependency:

$$
\alpha \leq \frac{\Delta_{\max }}{0.013 \cdot d_{w}^{-1.196} \cdot B^{2.026}} .
$$

It is possible in practice, regarding rough, finish or precision grinding, with known values of $d_{w}$ and $\mathrm{B}$, to determine accurately enough the maximum angle $\alpha$ at which the flatness deviation is within acceptable limits, and thus to avoid the defective polished products for this reason. In addition, the inverse problem becomes possible; determination of the value of angle $\alpha$, with known $\mathrm{d}_{\mathrm{w}}$ and $\mathrm{B}$, in the case of profile grinding of surfaces with pre-formed concavity. This allows for significant expansion of the technological capabilities of flat face grinding process. It should be noted that the knowledge of such processing parameter as flatness deviation is also of practical importance in the development of technological operation of flat face grinding as a part of a particular industrial process of a product. This refers to the determination of a number of passes $i$ with depth $t$ at the stage of finishing for reducing flatness deviation of the product surface:

$i=\frac{\Delta_{\max }}{t}$.

\section{Features of Multiple-Pass Flat Face Grinding}

Another technique that significantly reduces the contact area between wheel working surface and workpiece is the application of multiple-passes of grinding wheel with inclination of spindle axis; for this purpose, it is necessary to machine with additional cross-feed. Once again, COMPASS environment was employed. A purely geometric approach is used; it is considered that the depth of cut does not have an influence on the profile formation of the parts and it does not take into account the possible impact of the phenomena related to the manifestation of physical factors, e.g. elastic recovery [16]. In the simulation, it is also taken into consideration that the outer diameter of face wheel is not changed due to wear and traditional materials such as steel and hard alloys are considered as workpiece materials. Sections with concavity and residual ridges of certain height are formed on workpiece surface during multiple-pass grinding. So both concavity and residual ridges are characterized by a parameter $\mathrm{H}$, as shown in Fig. 7, where the grinding wheel is conventionally shown as a circle, and for convenience it is assumed that during the first pass the wheel axis coincides with one of the edges of the parts.

It should be noted that although the depth of cut does not directly influences parameter $\mathrm{H}$, it has a restrictive role on its limits. The value of $H$ is determined by factors such as wheel diameter $d_{w}$, inclination angle of spindle axis $\alpha$ and cross-feed $S_{\text {cf. Theoretically, the combination of these values }}$

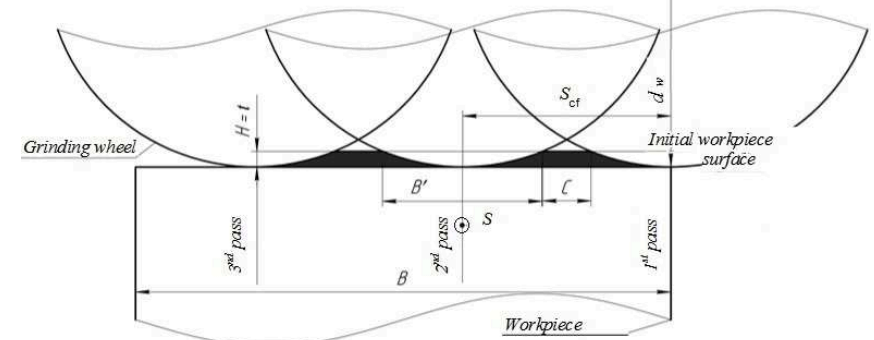

Fig. 7. Formation of surface in multiple-pass face grinding with $\mathrm{S}_{\mathrm{cf}}>\mathrm{B}^{\prime}$ provides parameter $\mathrm{H}$ in the range of values $0 \leq \mathrm{H} \leq \mathrm{t}$. It is convenient to express the value of cross-feed by fractions of the workpiece width surface being ground; not the entire width B is considered, but a fragment $\mathrm{B}^{\prime}$ that is formed in one pass with grinding depth $\mathrm{t}$, which, as will be shown, determines the maximum value of $\mathrm{S}_{\mathrm{cf}}$. It can be seen from Fig. 7 that if the value of cross-feed is greater than width $\mathrm{B}^{\prime}$, then height $\mathrm{H}$ will be maximum and $\mathrm{H}=\mathrm{H}_{\max }=\mathrm{t}$. Sections of width $\mathrm{C}$, unaffected by the grinding wheel, will remain on the machined surface; they constitute an unwanted area on the workpiece surface. Therefore, in order to remove this defect, the value of cross-feed should be limited in width B', i.e. the condition $\mathrm{S}_{\mathrm{cf}} \leq \mathrm{B}^{\prime}$ should be fulfilled.

The case where $\mathrm{S}_{\mathrm{cf}}=\mathrm{B}^{\prime}$ serves as a limit. In this case, similar to the former example, $\mathrm{H}=\mathrm{H}_{\max }=\mathrm{t}$, but areas with not ground surface will be practically absent. In Fig. 8, it can be seen that the formation of the machined surface during multiple-pass grinding presents similarities with the 
formation of roughness in the machining with edged tools, in cases where circular transition blade of a certain radius is involved. The difference lies in the fact that feed during turning is supplied uninterruptedly, while during multiple-pass grinding cross-feed is supplied periodically, on double stroke of the grinding machine table. Theoretically, depending on the value of $\mathrm{S}_{\mathrm{cf}}$, the height of residual ridges $\mathrm{H}$, on the surface of a part can detect form deviation and roughness. With the decrease of $S_{\text {cf }}$ the height of residual ridges will be correspondingly reduced, see Fig. 9.

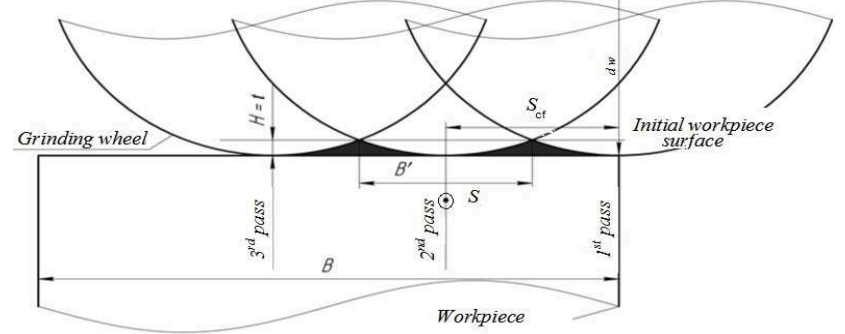

Fig. 8. Formation of surface in multiple-pass face grinding with $\mathrm{S}_{\mathrm{cf}}=\mathrm{B}^{\prime}$

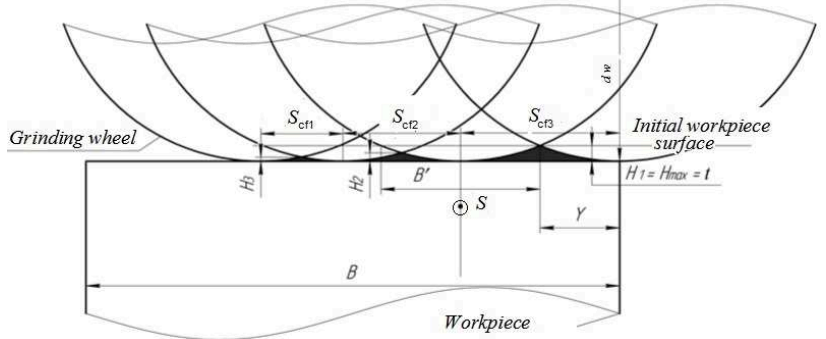

Fig. 9. Influence of $\mathrm{S}_{\mathrm{cf}}$ on $\mathrm{H}$, for $\mathrm{S}_{\mathrm{cfl}}=\mathrm{B}^{\prime}$ and $\mathrm{S}_{\mathrm{cf} 1}>\mathrm{S}_{\mathrm{cf} 2}>\mathrm{S}_{\mathrm{cf} 3}$

If the spindle inclination angle is $90^{\circ}$, face grinding wheel becomes a peripheral one, e.g., using cylindrical cup-shaped wheels, then the equation for determining the height of residual ridges during turning process is known [16], see first part of Eq. 5, where $\mathrm{H}(\mathrm{mm})$ is the height of residual ridges, $\mathrm{r}(\mathrm{mm})$ the radius at the cutter top and $\mathrm{S}(\mathrm{mm} / \mathrm{rev})$ the line feed. For this case, it is:

$H=r-\frac{\sqrt{4 r^{2}-S^{2}}}{2}=\frac{d_{w}-\sqrt{4\left(\frac{d_{w}}{2}\right)^{2}-S_{c f}^{2}}}{2}=\frac{d_{w}-\sqrt{d_{w}^{2}-S_{c f}^{2}}}{2}$.

Eq. 5 gives large errors and it is almost unusable, for angle $\alpha$ values close to zero, as in the examined grinding process. A series of computer experiments in COMPASS was carried out. Fig. 10, Fig. 11 and Fig. 12 outline functions $\mathrm{H}=f\left(\mathrm{~S}_{\mathrm{cf}}\right)$ and $\mathrm{H}=f\left(\mathrm{~d}_{\mathrm{w}}\right)$ as stepwise dependencies. It is worth noticing that the $\mathrm{H}=f(\alpha)$ equation is linear.

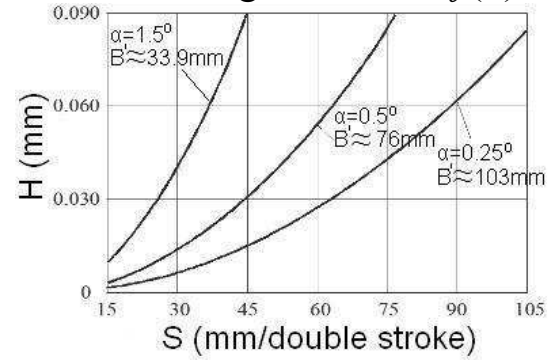

Fig. 10. $\mathrm{H}=f\left(\mathrm{~S}_{\mathrm{cf}}, \alpha\right)$ for $\mathrm{d}_{\mathrm{w}}=150 \mathrm{~mm}$ and $\mathrm{t}=0.09 \mathrm{~mm}$ for various combinations of $\alpha$ and $\mathrm{B}^{\prime}$

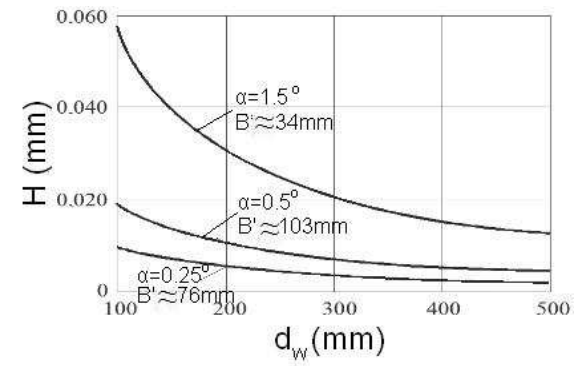

Fig. 11. $\mathrm{H}=f\left(\mathrm{~d}_{\mathrm{w}}, \alpha\right)$ for $\mathrm{S}_{\mathrm{cf}}=30 \mathrm{~mm} /$ double stroke and $\mathrm{t}=0.09 \mathrm{~mm}$ for various combinations of $\alpha$ and $\mathrm{B}^{\prime}$

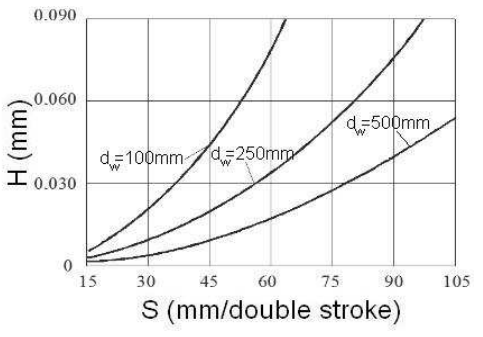

Fig. 12. $\mathrm{H}=f\left(\mathrm{~S}_{\mathrm{cf}}, \mathrm{d}_{\mathrm{w}}\right)$ for $\alpha=0.5^{\circ}$ and $\mathrm{t}=0.09 \mathrm{~mm}$ for various values of $\mathrm{d}_{\mathrm{w}}$

From the graphs it can be conducted that ridge height $\mathrm{H}$ decreases when $\mathrm{S}_{\mathrm{cf}}$ and $\alpha$ decrease and $\mathrm{d}_{\mathrm{w}}$ increases. If a shift of $\mathrm{S}_{\mathrm{cf}}$ according to the width of the part is applied during spark-out, for example, by a value equal half the feed in order to fulfill the process of grinding not "on trace", then the height of residual ridges can be substantially reduced even in the case of grinding with an inclination of the spindle axis. Using this approach the requirements for the values of roughness and form deviation can be accurately prescribed.

In the special case of sparking-out without spindle axis inclination, a mathematical empirical dependence can be proposed based on experimental results, reflecting the impact of the above examined factors on the height of residual ridges $\mathrm{H}$ :

$H=0.003 \cdot \alpha \cdot S_{c f}^{2.039} \cdot d_{w}^{-0.949}$.

This equation is obtained under the assumption that grinding depth does not exceed $0.1 \mathrm{~mm}$ and condition $\mathrm{S}_{\mathrm{cf}} \leq \mathrm{B}^{\prime}$ is valid. 


\section{Conclusions}

As a conclusion, it can be stated that the proposed technological developments make it possible to identify some features of the formation of micro- and macroprofile of the surface to-be-ground at flat face grinding with inclination of spindle axis. General equations are proposed that based on experimental work connect the parameters of micro- and macroprofile with processing conditions. This creates preconditions for further expansion of technological possibilities of flat face grinding. Further research pertains to the identification of the influence of grinding conditions on the length and width variation and consequently the area, of the contact of grinding wheel working surface with the workpiece surface.

\section{References}

[1] S. Malkin, C. Guo, Grinding Technology Theory and Applications of Machining with Abrasives, 2nd Edition, Industrial Press Inc., 2008.

[2] F. Klocke, Manufacturing Processes 2 Grinding, Honing, Lapping, Springer-Verlag, Berlin Heidelberg, 2009.

[3] T. Tawakoli, A. Rasifard, Dressing of Grinding Wheels, in: M.J. Jackson, J.P. Davim (Eds.), Machining with Abrasives, Springer-Verlag, Berlin Heidelberg, 2011.

[4] H.K. Toenshoff, B. Denkena, Basics of Cutting and Abrasive Processes, Springer-Verlag, Berlin Heidelberg, 2013.

[5] V.V. Loskutov, Grinding machines, (In Russian) Mechanical engineering, Moscow, 1976.

[6] M.S. Naerman, Handbook of young grinder, (In Russian) Higher school, Moscow, 1985.

[7] Y.S. Stepanov, B.S. Afonaciev, S.A. Kutsenko, G.A. Kharlamov, M.G. Podzolkov, Russian Federation Patent 2162788 (2001).

[8] A.I. Grabchenko, I.M. Pyzhov, V.G. Klimenko, Ukrainian Patent 81400 (2013).

[9] A.I. Grabchenko, I.M. Pyzhov, V.G. Klimenko, Ukrainian Patent 82805 (2013).

[10]A.I. Grabchenko, I.M. Pyzhov, V.A.Fedorovich, V.G. Klimenko, Ukrainian Patent 84041, 2013.

[11]A.I. Grabchenko, I.M. Pyzhov, V.A.Fedorovich, V.G. Klimenko, Ukranian Patent 746812012.

[12]A.I. Grabchenko, I.M. Pyzhov, L.S.Kravchenko, V.G. Klimenko, Ukranian Patent 764442013.

[13]I.M. Pyzhov, V.G. Klimenko, Investigation of features flatness deviation formation at flat face grinding (in Russian), Bulletin of SevNTU: collected scientific paper. 151 (2014) 134-139.

[14]I.M. Pyzhov, V.G. Klimenko, Some features of multiple-pass flat face grinding (in Russian), Cutting and tool in technological systems: International collected scientific papers, 84 (2014) 201210.

[15]A.I. Grabchenko, I.M Pyzhov, V.G. Klimenko, Computer-aided simulation of contact area of face grinding wheel with workpiece on flat grinding machines, Heavy engineering. Problems and trends of development (In Ukrainian), XI International Conference, Kramatorsk, 2013.

[16] A.I. Isaev, Microgeometry of surface at turning (in Rusian), Academy of Sciences of USSR, Moscow-Leningrad, 1950. 